\title{
Rheological properties of concentrated slurries of harvested, incubated and ruptured Nannochloropsis sp. cells
}

\author{
Srinivas Mettu ${ }^{1,2 \dagger}$, Shunyu Yao ${ }^{1 \dagger}$, Sam Q. K. Law ${ }^{2}$, Zheng Sun ${ }^{3}$, Peter J. Scales ${ }^{2}$, Muthupandian Ashokkumar ${ }^{1}$ and \\ Gregory J. O. Martin ${ }^{2^{*}}$ (D)
}

\begin{abstract}
Biorefining of microalgae biomass requires processing of high-solids (> 10\%) slurries. To date there is little knowledge of how processes for weakening and rupturing microalgae cells affect the rheological properties of these materials. To fill this gap in the literature, the rheological properties of concentrated slurries of marine microalgae Nannochloropsis sp. were investigated as a function of processing and solids concentration (12, 20 and $24 \% \mathrm{w} / \mathrm{w})$. Freshly harvested, incubated (autolysed), and high-pressure homogenised $(\mathrm{HPH})$ slurries were found to be shear thinning up to a shear rate of approximately $200 \mathrm{~s}^{-1}$. Viscosity increases were far more prominent for partially processed versus unprocessed algal pastes at the higher concentrations. Slurry viscosity as a function of cell volume fraction could not be fitted to the Krieger-Dougherty model due to a network structure resulting from extracellular polymeric substances (EPS) and the intracellular cell components released during incubation and cell rupture. The $24 \%$ slurry, which was near the close packing limit, was much more viscous than the less concentrated slurries when comprising whole cells (i.e. harvested and incubated slurries). Cell rupture by HPH completely altered the characteristics of the slurry, increasing the viscosity of even the less concentrated slurries, and producing irreversible shear thinning behaviour. The magnitude of the increases in viscosities and the irreversible shear thinning behaviour observed in this study, have significant implications for processing and optimising the solids concentration of algal slurries.
\end{abstract}

Keywords: Algae Biofuels, Incubation, Cell Rupture, Shear Rheology, Suspension Viscosity, Viscoelastic behaviour

\section{Background}

High costs associated either with complete drying or processing large volumes of dilute slurries of biomass hamper the economic viability of biofuel production from microalgae [1-4]. Processing partially dewatered suspensions can address this challenge by avoiding energy-intensive thermal drying and minimising capital costs [3, 4]. Hence, there is an emphasis on using high-solids slurries during both cell rupture and lipid extraction [1, 3-7]. Slurries around $20-25 \%$ solids (the typical limit of physical dewatering) are optimal for lowering the specific energy consumption per unit dry mass of algae processed or unit of lipid produced $[3,4]$. For

\footnotetext{
* Correspondence: gjmartin@unimelb.edu.au

† Srinivas Mettu and Shunyu Yao contributed equally to this work.

${ }^{2}$ Algal Processing Group, Department of Chemical Engineering, The

University of Melbourne, Parkville, Victoria 3010, Australia

Full list of author information is available at the end of the article
}

example, recently it was shown that high-solids slurries of the marine microalgae Nannochloropsis sp. can be efficiently ruptured using a high-pressure homogeniser (HPH) [7] or high-intensity ultrasonicators [6] in viscous slurries of up to 25 and $20 \%$ solids, respectively. In the latter study, it was found that the high-shear viscosity of a slurry of intact Nannochloropsis sp. cells increased by more than two orders of magnitude (from 85 to about $15,000 \mathrm{mPa} . \mathrm{s})$ when the solids concentration was increased from 20 to $25 \%$, limiting the effectiveness of ultrasonic rupture [6]. Such a high viscosity also introduces significant challenges for pumping and processing the slurries.

There have been a number of recent studies of the rheological behaviour of microalgae suspensions [8-12], including a few reporting rheological measurement of 20-25\% solids slurries [13-17] (Table 1). This concentration range is practically important for process

(c) The Author(s). 2019 Open Access This article is distributed under the terms of the Creative Commons Attribution 4.0 International License (http://creativecommons.org/licenses/by/4.0/), which permits unrestricted use, distribution, and 
intensification [4], and of rheological interest due to exponentially increasing viscosity resulting from close packing [18]. The slurries of various microalgae, including Nannochloropsis, have been found to be shear thinning, with a high-shear viscosity that is highly dependent on solids concentration [9, 11, 14, 15]. In these studies, cells were harvested via centrifugation, without the use of flocculants. The presence of flocculants can change the rheology of the suspensions by creating cross-links between cells. To this effect, Yap et al. [16] used mechanical shear to reduce the viscosity of chitosan-flocculated suspensions of Nannochloropsis sp. by breaking the network structure.

In the absence of externally added flocculants, the structuring of concentrated cell suspensions could occur through interactions between cells resulting from extracellular polymeric substances (EPS), which are polysaccharides and proteins released from or attached to the cells. The structure resulting from the presence of EPS is expected to be very weak compared to that induced by flocculants. In this case, the slurries would be expected to behave like colloidal suspensions of soft deformable particles stabilised by long chain non-ionic surfactants. However, this scenario is only applicable if the dewatered suspensions contain intact cells that have not gone through any processing. Current rheological studies of algae slurries have been limited to intact cells and there is a need to understand the effect of processing on suspension rheology.

For biorefinery applications in which algal lipids and proteins are to be recovered, intracellular contents are released from the cells during processing [19-23]. For example, in the case of hard-to-rupture cells like Nannochloropsis sp., slurries are incubated to weaken the cell walls and then mechanically ruptured by high-pressure homogenisation (Fig. 1) to allow extraction of the lipids $[6,7,24,25]$. Alternatively, pulsed electric fields can be used to permeabilise the cells for the recovery of proteins [21]. During these processes, cells release intracellular lipids, polysaccharides and proteins into the medium, which are expected to alter the rheology of the slurries. This effect has yet to be studied directly, although recently we observed that the high-shear viscosity of a 20\% solids Nannochloropsis sp. slurry increased 3-fold following ultrasonic cell rupture [6].

The release of intracellular material results in the formation of highly stable emulsions during the subsequent lipid extraction stage where solvents like hexane are used to recover non-polar lipids [26]. This, combined with the high viscosity of the slurry, creates difficulties for the recovery of lipid and solvent by centrifugation [5]. Apart from the high viscosity, the shear thinning behaviour of microalgae suspensions further complicates the design and implementation of lipid extraction

Table 1 Summary of research on the rheology of slurries of microalgal cells

\begin{tabular}{|c|c|c|c|c|}
\hline Study & Species & $\begin{array}{l}\text { Solids Concentration } \\
(w / w)\end{array}$ & $\begin{array}{l}\text { Volume } \\
\text { Fraction }\end{array}$ & Findings \\
\hline Wileman et al. [11], & $\begin{array}{l}\text { 1. Chlorella vulgaris, } \\
\text { 2. Nannochloropsis sp. }\end{array}$ & $0.05-8 \%$ & - & $\begin{array}{l}\text { The slurries were Newtonian fluids up to } 2 \% \text { solids } \\
\text { above which they showed shear thinning behaviour. }\end{array}$ \\
\hline Adesanya et al. [8], & 1. Scenedesmus obliquus & - & $6.8-15 \%$ & $\begin{array}{l}\text { The complex viscosity increased non-linearly with volume } \\
\text { fraction; attributed to the deformable nature and mutual } \\
\text { interaction between the cells in the suspension. }\end{array}$ \\
\hline Zhang et al. [12], & $\begin{array}{l}\text { 1. Fresh water and marine } \\
\text { Chlorella sp. }\end{array}$ & - & $0.7-4.3 \%$ & $\begin{array}{l}\text { The high-shear viscosities were low, around } 2 \text { times } \\
\text { the viscosity of water. }\end{array}$ \\
\hline Bernaerts et al. [9], & $\begin{array}{l}\text { 1. Chlorella vulgaris, } \\
\text { 2. Porphyridium cruentum, } \\
\text { 3. Odontella aurita }\end{array}$ & $8 \%$ & - & All the suspensions were shear thinning weak elastic gels. \\
\hline Cagney et al. [10], & $\begin{array}{l}\text { 1. Tetraselmis chuii, } \\
\text { 2. Chlorella sp. } \\
\text { 3. Phaeodactylum } \\
\text { tricornutum, }\end{array}$ & - & $5-20 \%$ & $\begin{array}{l}\text { The cell suspension viscosity increased with the } \\
\text { volume fraction. }\end{array}$ \\
\hline Wu and Shi [15], & 1. Chlorella pyrenoidosa & $2.5-25 \%$ & - & $\begin{array}{l}\text { The apparent viscosity of the cell suspension was rather } \\
\text { low showing Newtonian behaviour until } 15 \% \text { solids above } \\
\text { which the viscosity increased significantly }(\sim 1700 \mathrm{mPa} \text {.s } \\
\text { at } 25 \% \text { solids }) \text { showing shear thinning behaviour. }\end{array}$ \\
\hline $\begin{array}{l}\text { Schnieder and } \\
\text { Gerber [14] }\end{array}$ & 1. Nannochloropsis salina & $10-24 \%$ & - & The suspensions were shear thinning \\
\hline Chen et al. [13], & 1. Chlorella pyrenoidosa & $10-20 \%$ & - & $\begin{array}{l}\text { The apparent high-shear viscosity of a } 20 \% \text { solids suspension } \\
\text { was around } 40 \mathrm{mPa} \text {.s. }\end{array}$ \\
\hline Yap et al. [16], & 1. Nannochloropsis sp. & $25 \%$ & - & $\begin{array}{l}\text { The presence of chitosan resulted in a floc structure that } \\
\text { was broken by shear, hence the rheology was significantly } \\
\text { affected by pre-shear history of the suspension. }\end{array}$ \\
\hline
\end{tabular}




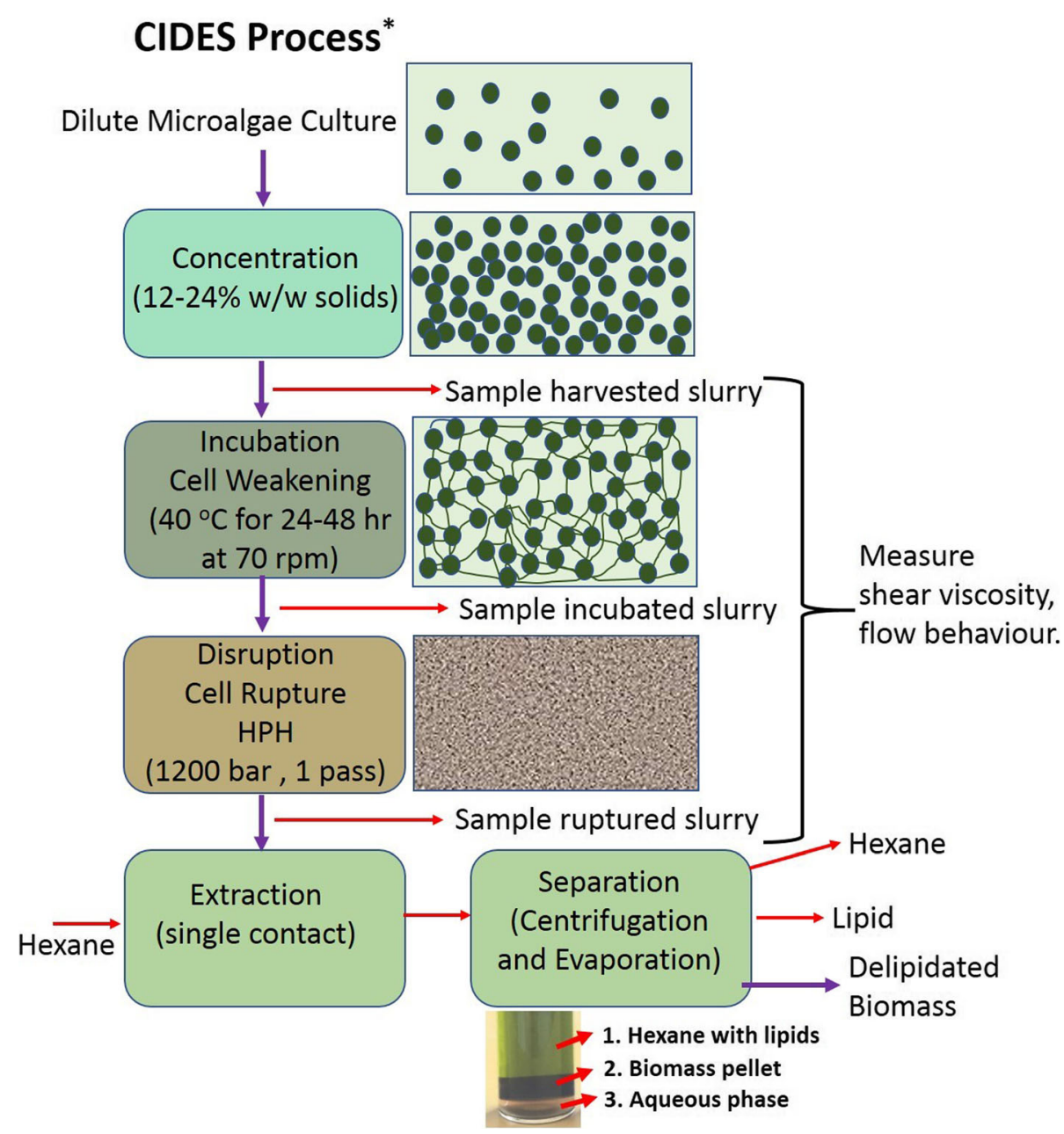

Fig. 1 Flow diagram of the CIDES method to process microalgae cultures to extract lipids, showing the Concentration, Incubation, Disruption, Extraction and Separation steps. The shear viscosity and viscoelastic behaviour of slurries of harvested, incubated and HPH ruptured Nannochloropsis sp. cells at 12, 20 and $24 \%$ solids concentrations were measured. The same initial slurry was sampled as it went through the different processing steps in the experiments. An image of hexane centrifugally separated from a hexane-in-microalgae emulsion is shown for reference

processes. Therefore, understanding the effect of processing on the rheology of algae slurries is a critical precursor to optimising the solids concentration during cell rupture and lipid extraction. Tuning the rheological behaviour of the slurries presents an opportunity to increase solvent recovery and improve the economics of the process. However, there appear to be no studies in the literature that have investigated changes in the rheological behaviour of high-solids microalgae slurries as a function of processing such as harvesting, incubation, cell rupture, or lipid extraction.

In this study, the rheological properties of slurries of Nannochloropsis sp. were measured as a function of solids concentration (at 12, 20 and 24\%) following harvest, cell weakening via incubation, and cell rupture by HPH. The low-shear and high-shear viscosities of the slurries were fitted as a function of wet volume fraction of cells using the Krieger-Dougherty model [18]. The shear thinning behaviour $\left(<1 \mathrm{~s}^{-1}\right)$ was fitted with a Herschel-Bulkley model [27] to obtain the consistency and flow behaviour indices.

\section{Methods}

\section{Microalgae biomass}

A strain of Nannochloropsis sp. [24] was grown indoors using a modified $f$ medium [25] in $15 \mathrm{~L}$ carboys at $20^{\circ} \mathrm{C}$ with a light:dark cycle of 14:10 h. Aquarium air pumps (Stellar 380D, Aqua One, China) were used to aerate the carboys at a flow rate of $190 \mathrm{~L} / \mathrm{h}$. A disc stack centrifuge (Separator OTC 2-02-137, GEA Westfalia, Italy) was used to harvest and concentrate the cultures into pastes after 14 days of growth. The nitrate levels in the cultures were typically depleted in $4-5$ days. The solids concentration of the harvested paste was determined by oven drying at $60^{\circ} \mathrm{C}$ [25]. The concentrated paste had a dry weight of $\sim 30 \% \mathrm{w} / \mathrm{w}$ solids. Paste was diluted with $3 \%$ 
$\mathrm{NaCl}$ solution to produce slurries of 12,20 and $24 \% \mathrm{w} / \mathrm{w}$, solids.

\section{Incubation}

Cells were weakened by incubation prior to rupture by high-pressure-homogenisation [24, 25]. Slurries of Nannochloropsis sp. (ca $24 \% \mathrm{w} / \mathrm{w})$ were incubated at $40{ }^{\circ} \mathrm{C}$ for $48 \mathrm{~h}$ with continuous mixing with an overhead stirrer (Stuart heat-stir CC162) at $70 \mathrm{rpm}$. The temperature of the slurry was maintained using a hot water bath placed on a hot plate fitted with a thermostat (Heidolph R2R 2012 Control). After incubation, a portion of the slurry was diluted with $3 \% \mathrm{NaCl}$ to prepare 20 and $12 \%$ solids slurries for rheological measurement.

\section{High-pressure homogenisation (HPH)}

A bench-top high-pressure homogeniser (GEA Panda 2 K NS1001L with Re + valve; GEA Niro Soavi, Parma, Italy) was used to rupture the cells [28]. Briefly, about $200 \mathrm{~g}$ of $24 \% \mathrm{w} / \mathrm{w}$ incubated slurries were passed once through the $\mathrm{HPH}$ at 1200 bar. After homogenisation, some of the slurry was diluted with $3 \% \mathrm{NaCl}$ to prepare 20 and $12 \%$ solids slurries for rheological measurement.

\section{Shear viscosity and viscoelastic behaviour}

Two types of rheological measurements were performed on the algae slurries using an MCR 702 Twin Drive from Anton-Paar rheometer. The first set measured the viscosity of slurries as a function of shear rate, and the second the storage and loss modulus as a function of applied shear stress. For shear viscosity measurements, the shear rates were varied from $0.005 \mathrm{~s}^{-1}$ to $300 \mathrm{~s}^{-} 1$.

The shear stress dependent storage and loss modulus were measured at a frequency of $1 \mathrm{rad} / \mathrm{s}(\sim 0.6 \mathrm{~Hz})$ in the shear stress range of $0.01-400 \mathrm{~Pa}$. The measurements were carried out until crossover of storage (elastic) and loss (viscous) modulus was achieved. The magnitudes of storage and loss modulus indicate the flow behaviour of slurries, with the cross-over indicating a transition from solid-like (elastic) behaviour to liquid-like (viscous) behaviour.

A vane-in-cup (ST12.5 \& C-CC17, Anton-Paar) geometry was used for both measurements. As explained in Yap et al. $(2016,16)$ vane-in-cup is the most suitable geometry for measuring the rheological behaviour of concentrated microalgae suspensions.

\section{Carbon and nitrogen analysis of supernatant}

Protein analysis of the slurry supernatants was performed using a LECO CNS (carbon, nitrogen, sulphur) analyzer. Supernatants were recovered from the biomass following centrifugation. A known amount of algae paste $(5.5 \mathrm{~g} \pm 0.5 \mathrm{~g})$ was centrifugated for $20 \mathrm{~min}$ at $5000 \mathrm{rpm}$ (Beckman Coulter X-30R centrifuge), after which the top layer was transferred to a known-weight vial and the bottom layer was discarded. The supernatant was then weighed $(1 \mathrm{~g} \pm 0.5 \mathrm{~g})$ and transferred into nickel boats and oven dried at $60{ }^{\circ} \mathrm{C}$ overnight. The nickel boats were put into ceramic boats then loaded into the LECO CNS analyser, where they were subjected to high-temperature combustion inside the furnace.

\section{Herschel-Bulkley model}

Shear thinning behaviour was quantitatively analysed by fitting the low shear $\left(<1 \mathrm{~s}^{-1}\right)$ data to a Herschel-Bulkley model (eqs. 3 and 4 ) to obtain a flow consistency index $(K)$ and flow behaviour index $(n)$.

$$
\eta=K|\dot{\gamma}|^{n-1}+\tau_{y}|\dot{\gamma}|^{-1}
$$

Here $\tau_{y}$ is the yield stress. The viscosity of a non-Newtonian fluid is given by eq. 1 , which is valid for shear stresses $>\tau_{y}$. For Newtonian fluids, $n=1$ and for shear thinning fluids, $n<1$.

\section{Results and discussion}

Shear viscosity of freshly harvested slurries

The shear viscosity of slurries of freshly harvested Nannochloropsis cells is shown Fig. 2 (a) at different solids concentrations. Herschel-Bulkley model parameters $(K$ and $n)$ for the low shear $\left(<1 s^{-1}\right)$ data are presented in Table 2. The consistency index $(K)$ and the yield stress $\left(\tau_{y}\right)$ increased whereas the flow behaviour index $(n)$ decreased for all the slurries as a function of increasing solids concentration, consistent with the literature $[8,10,11,15]$. The increase in consistency index and the yield stress with increase in solids concentration is, according to the literuatre, due to the formation of aggregate structures $[10,13,29]$. The decrease in flow behaviour index with increased solids indicates that the slurries become more shear thinning with an increase in solids concentration, which is consistent with literature [10]. The low shear viscosities (at $0.01 \mathrm{~s}^{-1}$ ) of the 12, 20 and $24 \% \mathrm{w} / \mathrm{w}$ solids harvested slurries were about 660 , 7800 and 23,600 times that of water, respectively. For all concentrations, the shear viscosity reached a minimum at a shear rate of about $200 \mathrm{~s}^{-1}$. The high-shear viscosities (at $300 \mathrm{~s}^{-1}$ ) of the 12, 20 and $24 \% \mathrm{w} / \mathrm{w}$ solids harvested slurries were about 10, 40 and 137 times that of water, respectively. The decrease in viscosity with shear was thus about 2 orders of magnitude. Although highly viscous, pumping of harvested slurries at $20-25 \%$ solids appears feasible with conventional centrifugal pumps as distinct from positive displacement pumps, as typical processing shear rates [11] of 5 to $300 \mathrm{~s}^{-1}$ will help reduce the viscosity.

The observed shear behaviour is typical of shear thinning colloidal suspensions, except that there was no 


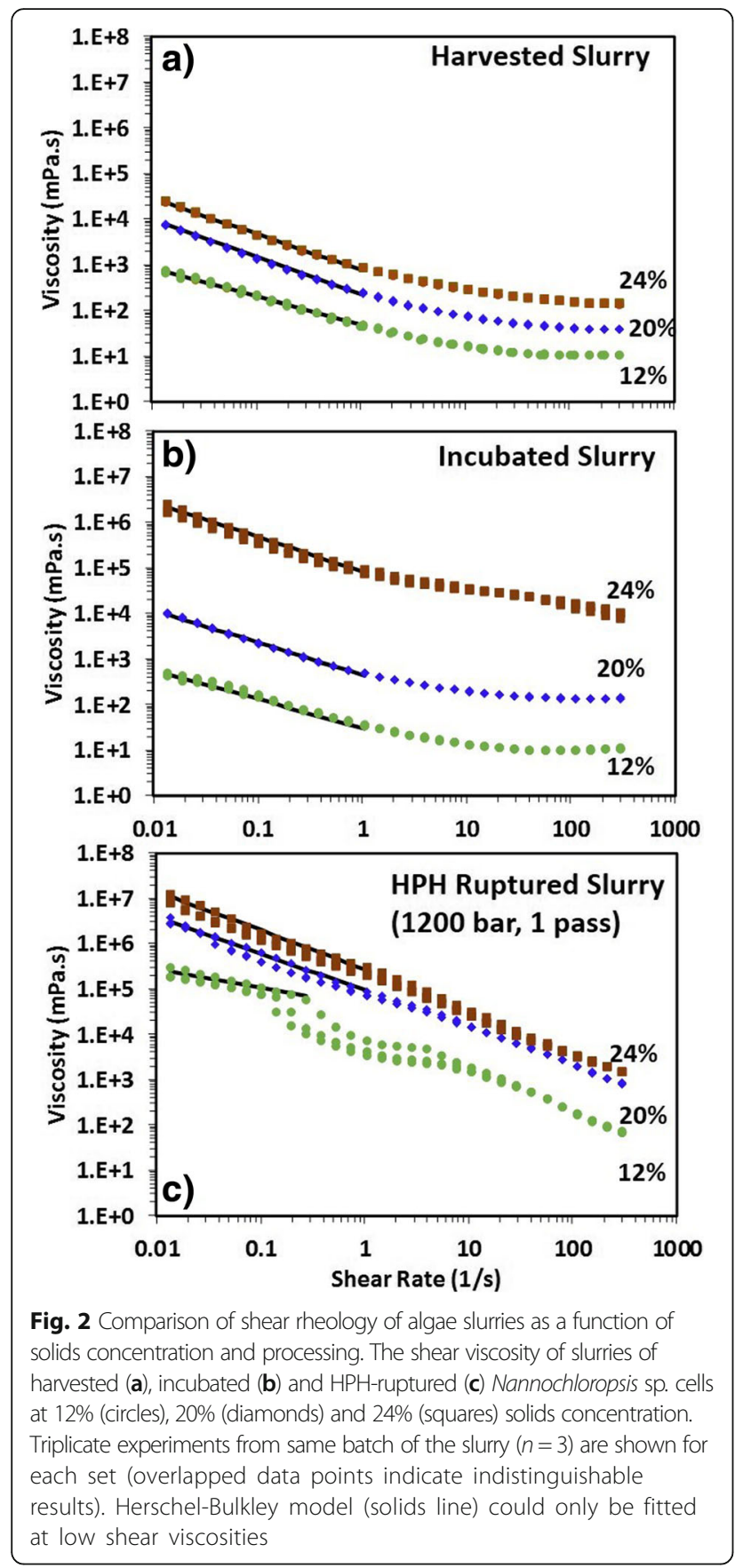

evidence of a zero-shear Newtonian region in which the viscosity stays constant at low shear rates. The intact cells in the slurry behave like deformable soft colloids $[30,31]$. For example, suspensions of whole blood show shear thinning behaviour, reaching a plateau Newtonian regime at shear rates above $100 \mathrm{~s}^{-1}$ [30]. It was found that the removal of proteins and fibrinogen from the blood reduced the viscosity when compared to whole blood. This observation indicates, perhaps as expected, that the network forming proteins and other molecules
Table 2 Consistency index (K), flow behaviour index ( $n$ ) and yield stress $\left(\tau_{y}\right)$ obtained by fitting the low-shear $\left(<1 \mathrm{~s}^{-1}\right)$ data to the Herschel-Bulkley model (eq. 1) fitting (Fig. 1)

\begin{tabular}{llllll}
\hline Slurry & Solids (\%) & $K\left(\right.$ m.Pa. $\left.{ }^{n}\right)$ & $n$ & $\tau_{y}(\mathrm{mPa})$ & Fitting $\mathrm{R}^{2}$ \\
\hline Harvested cells & 12 & 0.05 & 0.39 & 0 & 0.99 \\
& 20 & 0.22 & 0.18 & 4 & 0.98 \\
Incubated cells & 12 & 0.03 & 0.40 & 1 & 0.98 \\
& 24 & 0.75 & 0.21 & 5 & 0.99 \\
Ruptured cells & 20 & 0.44 & 0.30 & 4 & 0.99 \\
& 24 & 82 & 0.24 & 5 & 0.99 \\
& 20 & 40 & 0.58 & 1 & 0.91 \\
& 24 & 268 & 0.18 & 2 & 0.97 \\
\hline
\end{tabular}

present in the medium contribute to the structuring of the colloidal network. In our study, elemental analysis (CNS) of the supernatant of the harvested cells showed that there was negligible nitrogen at all solids concentrations and a small amount of carbon $(\sim 0.2-0.6 \%)$ present, as shown in Fig. 3. The absence of nitrogen confirms that there were no network-forming proteins in the supernatants of harvested cells. The carbon in the supernatant, which increased with an increase in solids concentration, indicates the presence of EPS-derived carbohydrates that could give rise to a weak gel-like network structure. The shear-thinning behaviour showed that such a gel-like network structure was sufficiently weak to be disrupted by shear. It was also found to restore itself very quickly, as confirmed by repetitive shear experiments, in which the viscosity profile was the same over a sequence of shear measurements performed on a single sample. This implies that the cells are packed within a weak reconfigurable network during centrifugation.

Concentration of the harvested Nannochloropsis sp. cells was performed in a disk stack centrifuge. During centrifugation, the compressive forces will achieve close packing by potentially deforming the cells and by expelling the interstitial water between the cells. The deformability of the cells means they could achieve higher volume fractions than hard spheres, which are limited to $\sim 74 \%$ volume fraction in close hexagonal packing. Assuming the packing fraction increased linearly with solids content, the harvested slurries at 12, 20 and 24\% $\mathrm{w} / \mathrm{w}$ solids had an approximate wet cell volume fraction of 36, 60 and $72 \%$; less than closed-packed hard spheres. This is consistent with a previous study by Yap et al. [16], that found Nannochloropsis sp. cells at $25 \%$ w/w solids concentration had a wet cell volume fraction of about $73 \%$.

\section{Shear viscosity of incubated slurries}

The cells of Nannochloropsis sp. are very hard to rupture due to their small size and strong cell walls [32]. To 

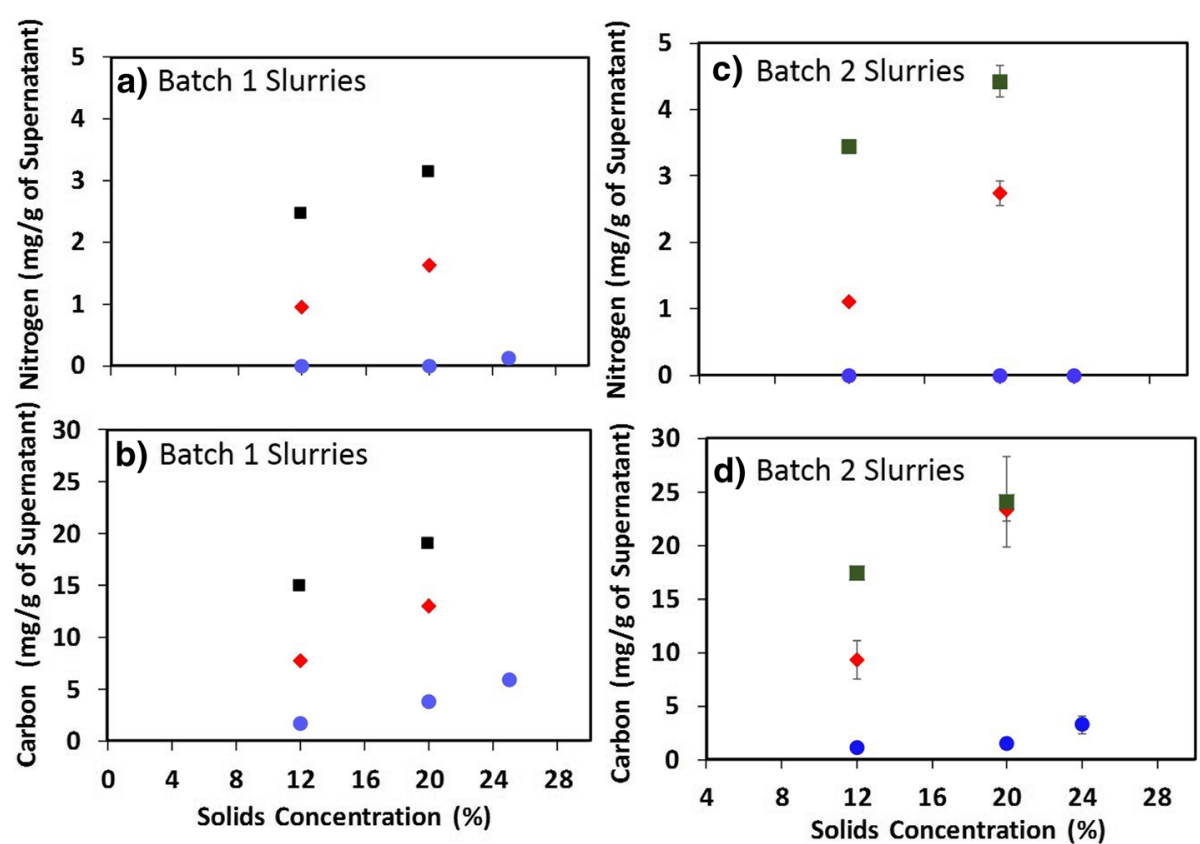

Fig. 3 Analysis of extracellular matter that can affect the rheology of algae slurries. Measured carbon and nitrogen (mg/g of supernatant) in the supernatant of harvested (circles), incubated (diamonds) and HPH ruptured slurries (squares) as a function of solids concentration. A single experimental run was carried out for the slurries (Batch 1) due to limited sample availability, whereas triplicate (3 runs from the same batch) experiments were carried out for a new batch of slurries (Batch 2). The data from both the batches show similar trends

weaken the cell walls, an incubation step was performed at $40^{\circ} \mathrm{C}$ for $48 \mathrm{~h}$ with constant mixing. The shear viscosity of the incubated slurries was then measured as a function of solids concentration (Fig. 2b). The viscosities of the 12 and $20 \%$ solids incubated slurries were reasonably similar to those of the harvested slurries and were also seen to plateau at high shear rates. At $24 \%$ solids however, the low shear and high shear viscosity of incubated slurry were 90-fold and 73-fold higher that of the freshly harvested slurry, respectively. Also, the shear viscosity of the incubated slurry decreased continuously with an increase in shear, without showing a plateau at high shear rates.

During incubation, Nannochloropsis sp. cells remain intact, even though the cell walls are weakened [24]. Importantly, some of the intracellular proteins and polysaccharides are also released into the medium during incubation (Fig. 1). At high concentrations, these intracellular biopolymers can act as a cohesive matrix to form a strong gel like network structure with the cells [30]. The data here, indicate that below the close-packing volume fraction (12 and $20 \%$ solids), the released intracellular material has little effect on the rheology. This indicates that at lower concentrations the released intracellular material is not able to form a cohesive network structure. However, at close packing (24\%) solids, the intracellular material is sufficiently concentrated, and/or the cells are adequately close to each for a strong network structure to be formed, as is evident from the high viscosity and shear thinning behaviour in Fig. 2 (b). Somewhat similarly, Yap et al. [16], found that chitosan-flocculated Nannochloropsis sp. cells at 25\% solids displayed shear thinning with increasing shear, without any plateau. The rheological behaviour of the concentrated incubated and chitosan-flocculated slurries is consistent with colloidal suspension of soft particles [33] stabilised by long chain polymers.

Such a dramatic increase in viscosity upon incubation at high solids presents a challenge for processing. For example, recently it was observed that ultrasonic cell rupture is not very efficient for $25 \%$ solids slurries due to increased ultrasound attenuation with increased viscosity. Hence, to reduce process volumes without increasing the viscosities to problematic levels, diluting the incubated slurries to $20 \%$ solids, or only dewatering to this level in the first place, may be preferable.

\section{Shear viscosity of slurries of HPH-ruptured cells}

The viscosities of slurries of HPH ruptured cells are presented in Fig. 2 (c). Interestingly, the magnitude of the viscosity of the $24 \%$ solids incubated slurry did not change much with cell rupture by $\mathrm{HPH}$. While the low-shear viscosity of the HPH slurry was 5 times higher than the low-shear viscosity of the incubated slurry, the high-shear viscosity was 5 times 
lower. This could be attributed to the fact that the cell rupture, whilst releasing intracellular molecules, also releases water. It also indicates that the network forming molecules are preferentially released during incubation. In comparison, cell rupture increased the low-shear viscosity of the $20 \%$ slurry by 2 orders of magnitude and the high-shear viscosity 5 -fold. Previously, we observed a similar increase in the low-shear and high-shear viscosities of a $20 \%$ solids slurry of Nannochloropsis sp. cells that were ruptured by high intensity ultrasonication [6]. The behaviour of the $12 \%$ solids slurry was similar to that of the $20 \%$ solids slurry, where the apparent low-shear viscosity increased by more than 2 orders of magnitude and the high-shear viscosity increased 7 -fold after cell rupture by $\mathrm{HPH}$.

The slurries of HPH ruptured cells showed shear thinning behaviour at all solids concentrations, without showing a plateau at high shear (Fig. 2c). Small variations in the shear thinning behaviour were seen on successive experimental runs, with almost negligible variation between repeated runs at high shear. This is consistent with reversible shear-induced breakdown of a cohesive flocculated network.

During the break up of cells by high-pressure homogenisation, intercellular lipids, proteins, nucleic acids and polysaccharides are released into the medium, and cell wall and membrane debris is produced. Hence, slurries of HPH-ruptured cells are complex mixtures of cell components with no geometrical uniformity to their structure. There is likely to be a tendency for the cell debris particles to interact, explaining why the rheology of these slurries is like that of a flocculated suspension of geometrically non-uniform particles [10].

The change in viscosity and shear behaviour with $\mathrm{HPH}$ has important implications for downstream lipid extraction. The increased viscosity of the slurries following $\mathrm{HPH}$ adversely affects physical recovery of the lipid and solvent by centrifugation [5]. During lipid extraction, hexane-in-microalgae emulsions are formed. During centrifugation, the viscosity of slurry continuously increases as hexane is removed, further increasing the barrier to coalescence and droplet migration [5]. Therefore, the initial solids concentration of the HPH ruptured slurry and its shear behaviour significantly influence hexane recovery. Recently, we have shown that the maximum hexane recovery was around 90\% [5], with the remaining $10 \%$ of the hexane trapped in the viscous residual slurry. While cell rupture by $\mathrm{HPH}$ is most economical and energy efficient for high-solids slurries $[7,25,34]$, it may be that a slight dilution prior to lipid extraction may help increase solvent recovery.
Viscoelastic behaviour of harvested, incubated and HPH ruptured slurries

Oscillatory shear stress measurements (at $1 \mathrm{rad} / \mathrm{s}$ or 0.6 $\mathrm{Hz}$ ) were performed on the slurries as a function of solids concentration and processing (Fig. 4). Processing of the slurries, as schematically shown in Fig. 4, involved
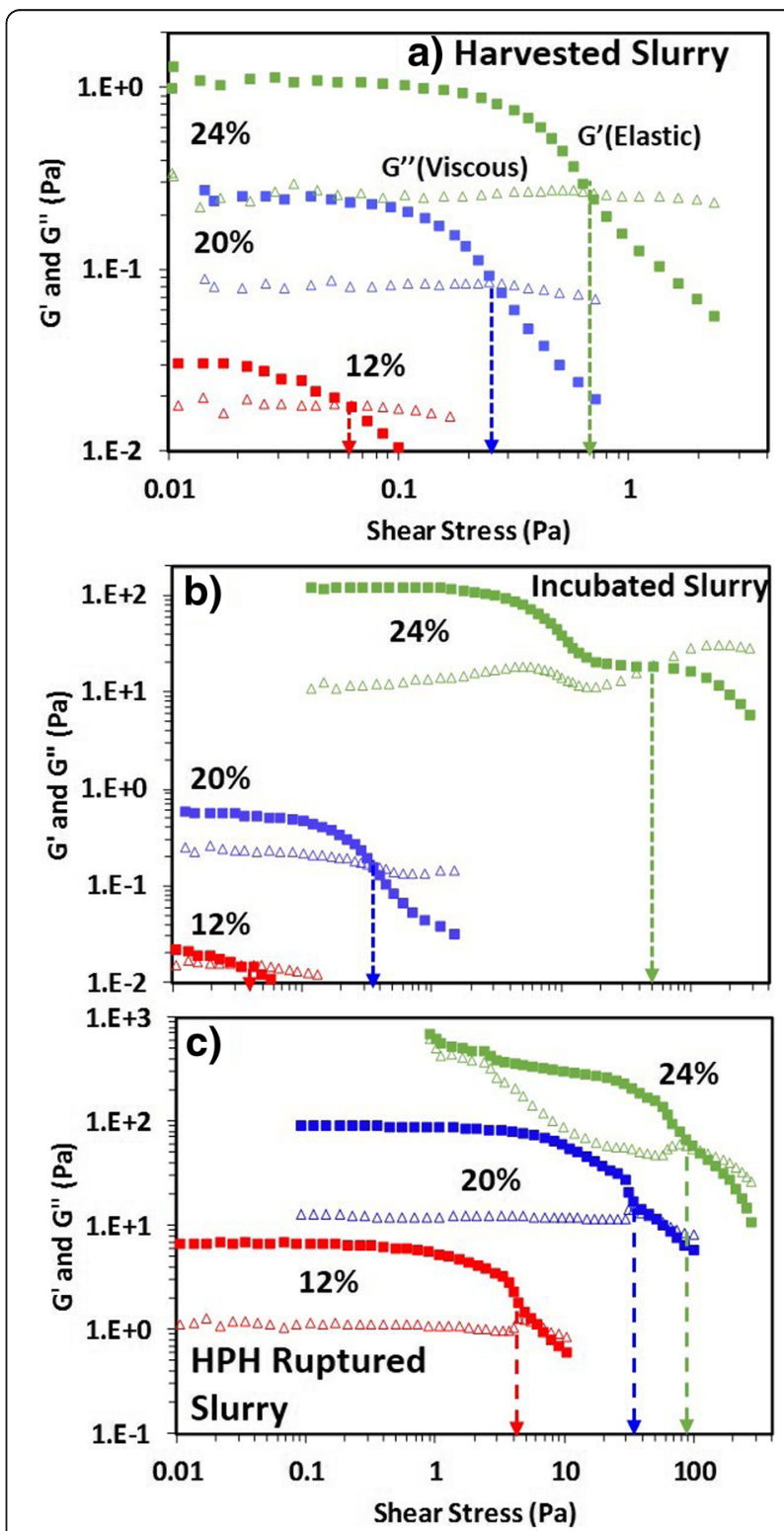

Fig. 4 Viscoelastic behaviour of algae slurries as a function of solids concentration and processing. Data were obtained from shear stress sweeps at $1 \mathrm{rad} / \mathrm{s}$ that show the storage (elastic) and loss (viscous) moduli of the slurries of harvested (a), incubated (b) and HPH ruptured (c) Nannochloropsis sp. cells at 12,20 and $24 \%$ solids concentrations. All the slurries were elastic in nature, where the elastic modulus ( $G^{\prime}$, solid squares) was greater than the viscous modulus ( $G$ ", hollow triangles) at low shear. The crossover between the viscous and elastic moduli, indicated by dashed arrow lines, is often used to characterise the gel-like to fluid-like transition. Duplicate data gave similar results, with a single data set shown for clarity 
incubation to weaken the cell walls and rupturing the cells by $\mathrm{HPH}$ to release the intracellular lipids. All the slurries displayed qualitatively similar behaviour. At the low frequency used in these experiments, the slurries are assumed to be in the linear viscoelastic (LVE) region based on previous studies in this laboratory on the same materials [16]. This was found to be the case, with the elastic and viscous moduli constant for small applied shear stresses (LVE). All the slurries showed elastic solid-like behaviour, where the elastic modulus was higher than the viscous modulus at low shear stress and lower than the viscous modulus, which increased at high shear rates. However, the magnitude of the elastic and viscous moduli and the crossover shear stress varied both with solids concentration and processing history. The high elastic modulus relative to the viscous modulus of the slurries reflects a well-structured gel-like system where there is a strong association between the cells/debris in the suspensions.

For the freshly harvested slurries, the results indicate the presence of a relatively weak gel-like network that can be readily broken to induce flow. For the $12 \%$ harvested slurry, there was only a small (2-fold) difference between the viscous and loss moduli and the shear stress needed to induce flow was only $0.06 \mathrm{~Pa}$ (Fig. 4a). At higher solids (20 and 24\%), the elastic modulus was 8 and 32 times greater and the crossover shear stress 4 and 10-fold times higher than the $12 \%$ slurry, respectively. Similar to the shear viscosity measurements, the weak gel-like network structure that was disrupted by the applied shear stress was found to restore very quickly. Successive viscoelastic behaviour experiments on the same sample resulted in no change in response or crossover point. This is again consistent with the cells packing into a weak reversible network during centrifugal harvesting.

The viscoelastic behaviour of the incubated slurries was highly dependent on cell packing (Fig. 4b). The viscoelastic behaviour of the 12 and $20 \%$ solids slurries was similar to the harvested slurries. However, the $24 \%$ solids incubated slurry, which has a volume fraction at the limit of close packing, had elastic and viscous moduli around 230- and 70-fold higher than the 20\% solids slurry, respectively.

The viscoelastic behaviour of HPH ruptured slurries is shown in Fig. 4c. The elastic and viscous moduli of the 12 and $20 \%$ solids slurries were significantly higher than the harvested and incubated slurries. The magnitude of the difference between the elastic and viscous moduli also increased when compared to the harvested and incubated slurries. The crossover shear stress, associated with break-down of flocculated structure resulting in flow, also increased compared to the harvested and incubated slurries. As discussed, this increase is the result of the release of intracellular components into the medium along with the production of cell debris. Some irreversibility in the strong gel-like network structure was also evident, where the crossover shear stress for flow was reduced on repeated measurements of the same sample. Yap et al. [16] observed similar shear-induced rheological changes for chitosan-flocculated, high-solids microalgae slurries. Thus, even in the absence of a flocculant such as chitosan, these results demonstrate the possibility of altering the rheology of HPH-ruptured using shear, to facilitate subsequent processing such as lipid extraction. Further experiments to quantify the solvent recovery from sheared versus non-sheared $\mathrm{HPH}$ ruptured slurries would be useful in confirming this opportunity.

\section{Low-shear and high-shear viscosity as a function of solids concentration}

The relationship between viscosity and solids concentration was compared for the slurries of differently treated cells. The volume fractions of the harvested cells were estimated from the solids concentration to be $0.36,0.60$ and 0.72 , for the slurries at 12,20 and $24 \%$ solids, respectively. The viscosity of suspensions generally increases with an increase in the volume fraction $(\phi)$ of suspended particles. For dilute suspensions $(\phi \leq 0.05)$, the viscosity increases linearly with volume fraction $(\phi)$ as given by Einstein's equation (eq. 2).

$$
\eta=\eta_{o}(1+\alpha \phi)
$$

Here, $\eta_{o}$ is the viscosity of the suspending medium and $\alpha$ is the intrinsic viscosity of the medium and $\alpha$ $=2.5$ for rigid, non-interacting solid spheres. However, when the suspended particles are either charged or stabilised by adsorbed/grafted polymers, electrical double layer/steric forces act between the colloids, resulting in mutual interaction. Hence, the presence of charge or polymers, either on the surface of particles or in the suspending medium, significantly affects the viscosity. For example, in the case of charged particles, the salt concentration affects the double layer thickness, which in turn affects the low-shear viscosity [35]. The viscosities of charged particles in suspension are predicted using the effective volume fraction, which is dependent on the Debye length. In the case of sterically stabilised colloidal particles, the thickness of the brush layer affects the mutual interaction between the dispersed colloids. In this case, an effective hard-sphere model is used to predict the viscosities as a function of volume fraction [36]. The effective hard-sphere model does not work well at high 
volume fractions due to the compression of steric brush layers due to close packing [37]. It does not work well when the colloidal particles are soft. Hence for volume fractions as high as those of the slurries of soft colloids studied here, the Krieger-Dougherty model is generally used, whereby:

$$
\eta=\eta_{o}\left(1-\frac{\phi}{\phi_{m}}\right)^{-\alpha \phi_{m}}
$$

Here, $\phi_{m}$ is the maximum packing volume fraction.

It was found that none of the low-shear or high-shear viscosity conformed to the Krieger-Dougherty model, regardless of processing stage (Additional file 1: Figure S1). This is attributed to the fact that the KriegerDougherty model assumes non-interacting, rigid particles, which is not valid for these slurries due to the interaction between cells via EPS and components in the medium. In addition, the slurries of ruptured cells have little or no geometrical uniformity. From the analysis of the data presented here, it is possible to develop a conceptual picture of the effect of cell concentration and processing on the rheology of Nannochloropsis sp. slurries (Fig. 5). Understanding the changes in slurry rheology during the processing will be beneficial in determining the optimal solids concentration to be used in each processing stage to minimise the energy input of the process. It is expected that the major mechanisms identified here, would be generally applicable to slurries of other microalgae and micro-organisms.

\section{Conclusions}

Economical processing of microalgae requires the use of high-solids slurries that reduce process volumes and energy costs. The shear rate and shear stress dependent rheology of concentrated microalgae suspensions is critical during processing. The rheology and viscoelastic behaviour of the slurries of Nannochloropsis sp. were compared at various solids concentrations (12, 20 and $24 \%$ ) as a function of processing. The slurries were shear thinning at all solids concentrations, with a shear-independent viscosity above about $200 \mathrm{~s}^{-1}$. For the less concentrated slurries, the increase in viscosity was significant only after the cell rupture stage, whereas for the $24 \%$ solid slurry there was a significant increase in viscosity during incubation. The results suggest that harvested cells form a weak matrix that is strengthened by the release of intracellular components during incubation, particularly for slurries near the limit of close packing (i.e. 24\% solids). Cell rupture changes the rheological properties of the slurries, which become highly viscous and show irreversible shear thinning behaviour. From a processing perspective, $24 \%$ slurries are practical to pump and process via high-pressure homogenisation, however the increased viscosity upon incubation and rupture may require dilution prior to lipid extraction step to ensure high rates of solvent recovery.

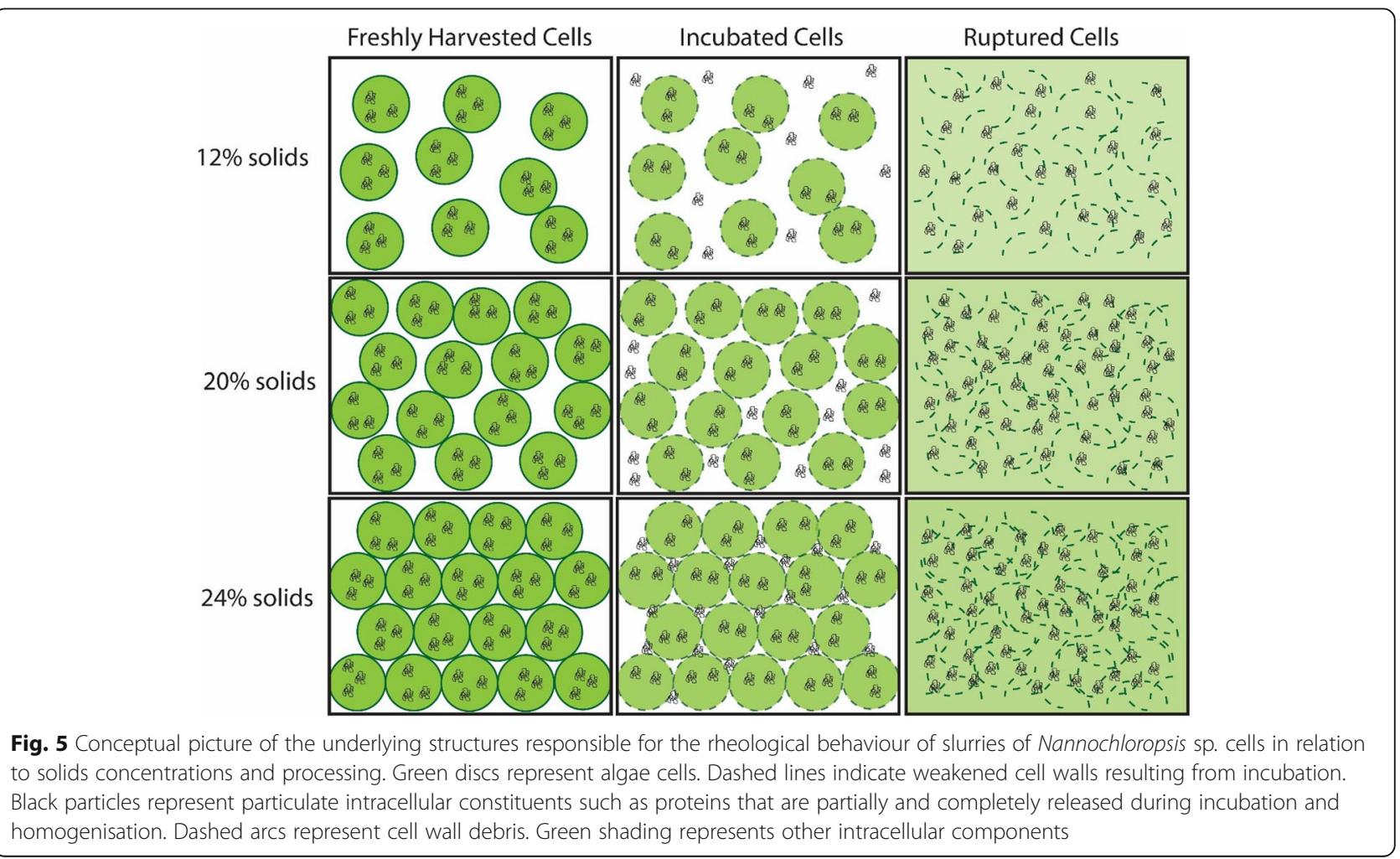




\section{Additional file}

Additional file 1: Figure S1. Fitting Krieger-Dougherty model to the low (a) and high shear (b) viscosities of the slurries of harvested, incubated and HPH ruptured Nannochloropsis sp. cells at 12,20\% and 24\% solids concentrations. The only fitting parameter is the intrinsic viscosity (a) which is shown for each fit line. The ruptured paste does not follow the model due to geometrical non-uniformity (inset). Figure S2. Schematic (not to the scale) of microalgae cell suspension and chain formation through proteins and polysaccharides present in the supernatant of the suspension. Figure S3. Fitting of Cross viscosity equation to the shear viscosities for the slurries of harvested, incubated and $\mathrm{HPH}$ ruptured Nannochloropsis sp. cells at $12,20 \%$ and $24 \%$ solids concentrations, harvested (a), incubated (48 hrs at $40^{\circ} \mathrm{C}$ ) (b), ruptured by HPH (c). (DOCX $390 \mathrm{~kb}$ )

\section{Abbreviations}

CNS: Carbon, nitrogen, sulphur; EPS: Extracellular polymeric substances; $\mathrm{HPH}$ : High-pressure homogenisation; LVE: Linear viscoelastic

\section{Acknowledgements}

This work was performed in part at the PFPC (Particulate Fluids Processing (entre) at the University of Melbourne. The authors would like to thank Dr. David R. A. Hill for his contribution in culturing and harvesting the microalgae.

\section{Funding}

We thank the Australian Research Council (ARC) for providing funding through Discovery Projects Grant Scheme (DP170103791) and the University of Melbourne for providing infrastructure support.

\section{Availability of data and materials}

The data files for all data presented in the manuscript are available from the corresponding author upon request.

\section{Authors' contributions}

SM, GM, MA, PS designed the experiments. SM and SY carried out the experiments and analysis. All the authors contributed to the writing of the manuscript. All authors read and approved the final manuscript.

\section{Competing interests}

The authors declare that they have no competing interests.

\section{Publisher's Note}

Springer Nature remains neutral with regard to jurisdictional claims in published maps and institutional affiliations.

\section{Author details}

'Sonochemistry Group, School of Chemistry, The University of Melbourne, Parkville, Melbourne, Victoria 3010, Australia. ${ }^{2}$ Algal Processing Group, Department of Chemical Engineering, The University of Melbourne, Parkville, Victoria 3010, Australia. ${ }^{3}$ International Research Center for Marine Biosciences, Ministry of Science and Technology, Shanghai Ocean University, Shanghai 201306, China.

Received: 23 November 2018 Accepted: 6 March 2019 Published online: 08 May 2019

\section{References}

1. Adam F, Abert-Vian M, Peltier G, Chemat F. "Solvent-free" ultrasoundassisted extraction of lipids from fresh microalgae cells: A green, clean and scalable process. Bioresource Technology. 2012;114(Supplement C):457-65.

2. Chisti Y. Constraints to commercialization of algal fuels. J Biotechnol. 2013; 167(3):201-14

3. Coons JE, Kalb DM, Dale T, Marrone BL. Getting to low-cost algal biofuels: A monograph on conventional and cutting-edge harvesting and extraction technologies. Algal Research. 2014;6(Part B):250-70.

4. Martin GJO. Energy requirements for wet solvent extraction of lipids from microalgal biomass. Bioresource Technology. 2016;205(Supplement C):40-7.
5. Law SQK, Chen B, Scales PJ, Martin GJO. Centrifugal recovery of solvent after biphasic wet extraction of lipids from a concentrated slurry of Nannochloropsis sp. biomass. Algal Research. 2017;24(Part A):299-308.

6. Yao S, Mettu S, Law SQ, Ashokkumar M, Martin GJ. The effect of highintensity ultrasound on cell disruption and lipid extraction from high-solids viscous slurries of Nannochloropsis sp. biomass. Algal Res. 2018;35:341-8.

7. Yap BHJ, Dumsday GJ, Scales PJ, Martin GJO. Energy evaluation of algal cell disruption by high pressure homogenisation. Bioresource Technology. 2015: 184(Supplement C):280-5.

8. Adesanya VO, Vadillo DC, Mackley MR. The rheological characterization of algae suspensions for the production of biofuels. J Rheol. 2012;56(4):925-39.

9. Bernaerts TM, Panozzo A, Doumen V, Foubert I, Gheysen L, Goiris K, et al. Microalgal biomass as a (multi) functional ingredient in food products: rheological properties of microalgal suspensions as affected by mechanical and thermal processing. Algal Res. 2017:25:452-63.

10. Cagney N, Zhang T, Bransgrove R, Allen MJ, Balabani S. Effects of cell motility and morphology on the rheology of algae suspensions. J Appl Phycol. 2017;29(3):1145-57.

11. Wileman A, Ozkan A, Berberoglu H. Rheological properties of algae slurries for minimizing harvesting energy requirements in biofuel production. Bioresour Technol. 2012;104:432-9.

12. Zhang $X$, Jiang Z, Chen L, Chou A, Yan H, Zuo YY, et al. Influence of cell properties on rheological characterization of microalgae suspensions. Bioresour Technol. 2013;139:209-13.

13. Chen $H, F u$ Q, Liao Q, Zhang H, Huang $Y$, Xia A, et al. Rheological properties of microalgae slurry for application in hydrothermal pretreatment systems. Bioresour Technol. 2018;249:599-604.

14. Schneider N, Gerber M. Correlation between viscosity, temperature and total solid content of algal biomass. Bioresour Technol. 2014;170:293-302.

15. Wu Z-y, Shi X-m. Rheological properties of Chlorella pyrenoidosa culture grown heterotrophically in a fermentor. J Appl Phycol. 2008;20(3):279-82.

16. Yap BH, Martin GJ, Scales PJ. Rheological manipulation of flocculated algal slurries to achieve high solids processing. Algal Res. 2016;14:1-8.

17. Zhang $\mathrm{H}$, Liao Q, Fu Q, Chen H, Huang Y, Xia A, et al. Rheological properties of microalgae slurry under subcritical conditions for hydrothermal hydrolysis systems. Algal Res. 2018:33:78-83.

18. Krieger IM, Dougherty TJ. A mechanism for non-Newtonian flow in suspensions of rigid spheres. Transactions of the Society of Rheology. 1959:3(1):137-52.

19. Vanthoor-Koopmans M, Wijffels RH, Barbosa MJ, Eppink MH. Biorefinery of microalgae for food and fuel. Bioresour Technol. 2013;135:142-9.

20. Jiménez Callejón MJ, Robles Medina A, Macías Sánchez MD, Hita Peña E, Esteban Cerdán L, González Moreno PA, et al. Extraction of saponifiable lipids from wet microalgal biomass for biodiesel production. Bioresource Technology. 2014;169(Supplement C):198-205.

21. Goettel M, Eing C, Gusbeth C, Straessner R, Frey W. Pulsed electric field assisted extraction of intracellular valuables from microalgae. Algal Res. 2013:2(4):401-8

22. Dong T, Knoshaug EP, Davis R, Laurens LML, Van Wychen S, Pienkos PT, et al. Combined algal processing: a novel integrated biorefinery process to produce algal biofuels and bioproducts. Algal Res. 2016;19:316-23.

23. Dong T, Knoshaug EP, Pienkos PT, Laurens LML. Lipid recovery from wet oleaginous microbial biomass for biofuel production: a critical review. Appl Energy. 2016:177:879-95.

24. Halim R, Webley PA, Martin GJO. The CIDES process: Fractionation of concentrated microalgal paste for co-production of biofuel, nutraceuticals, and high-grade protein feed. Algal Research. 2016;19(Supplement C):299-306.

25. Olmstead ILD, Kentish SE, Scales PJ, Martin GJO. Low solvent, low temperature method for extracting biodiesel lipids from concentrated microalgal biomass. Bioresource Technology. 2013;148(Supplement C):615-9.

26. Law SQ, Mettu S, Ashokkumar M, Scales PJ, Martin GJ. Emulsifying properties of ruptured microalgae cells: barriers to lipid extraction or promising biosurfactants? Colloids and Surfaces B: Biointerfaces; 2018.

27. Herschel WH, Bulkley R. Konsistenzmessungen von Gummi-Benzollösungen. Kolloid-Zeitschrift. 1926:39(4):291-300.

28. Spiden EM, Yap BHJ, Hill DRA, Kentish SE, Scales PJ, Martin GJO. Quantitative evaluation of the ease of rupture of industrially promising microalgae by high pressure homogenization. Bioresource Technology. 2013; 140(Supplement C):165-71.

29. Soulies A, Pruvost J, Legrand J, Castelain C, Burghelea TI. Rheological properties of suspensions of the green microalga Chlorella vulgaris at various volume fractions. Rheol Acta. 2013;52(6):589-605. 
30. Chien S, Usami S, Taylor HM, Lundberg JL, Gregersen Ml. Effects of hematocrit and plasma proteins on human blood rheology at low shear rates. J Appl Physiol. 1966;21(1):81-7.

31. Winkler RG, Fedosov DA, Gompper G. Dynamical and rheological properties of soft colloid suspensions. Curr Opin Colloid Interface Sci. 2014;19(6):594-610.

32. Yap BHJ, Crawford SA, Dagastine RR, Scales PJ, Martin GJO. Nitrogen deprivation of microalgae: effect on cell size, cell wall thickness, cell strength, and resistance to mechanical rupture. J Ind Microbiol Biotechnol. 2016:43(12):1671-80.

33. Cloitre M, Borrega R, Monti F, Leibler L. Structure and flow of polyelectrolyte microgels: from suspensions to glasses. Comptes Rendus Physique. 2003; 4(2):221-30

34. Yap BHJ, Crawford SA, Dumsday GJ, Scales PJ, Martin GJO. A mechanistic study of algal cell disruption and its effect on lipid recovery by solvent extraction. Algal Research. 2014:5(Supplement C):112-20.

35. Horn F, Richtering W, Bergenholtz J, Willenbacher N, Wagner N. Hydrodynamic and colloidal interactions in concentrated charge-stabilized polymer dispersions. J Colloid Interface Sci. 2000;225(1):166-78.

36. Buscall R. An effective hard-sphere model of the non-Newtonian viscosity of stable colloidal dispersions: comparison with further data for sterically stabilised latices and with data for microgel particles. Colloids Surf A Physicochem Eng Asp. 1994:83(1):33-42.

37. Mewis J, Vermant J. Rheology of sterically stabilized dispersions and latices. Progress in organic coatings. 2000;40(1-4):111-7.

Ready to submit your research? Choose BMC and benefit from:

- fast, convenient online submission

- thorough peer review by experienced researchers in your field

- rapid publication on acceptance

- support for research data, including large and complex data types

- gold Open Access which fosters wider collaboration and increased citations

- maximum visibility for your research: over $100 \mathrm{M}$ website views per year

At BMC, research is always in progress.

Learn more biomedcentral.com/submissions 